\title{
Red cell distribution width and chronic heart failure: prognostic role beyond echocardiographic parameters
}

\section{Red cell distribution width e scompenso cardiaco cronico: ruolo prognostico oltre i parametri ecocardiografici}

\author{
Enrico Vizzardi, Edoardo Sciatti, Ivano Bonadei, Natalia L. Pezzali, Carlo M. Lombardi, \\ Marco Metra
}

\author{
Department of Medical and Surgical Specialties, Radiological Sciences and Public Health, \\ Section of Cardiovascular Diseases, University of Brescia, Italy
}

\begin{abstract}
Aim. Red cell distribution width (RDW) is a measure of anisocytosis. Higher values are robustly associated to adverse outcome in several conditions, including chronic heart failure (HF). The present study aimed to compared its prognostic role with that of echocardiographic parameters in this kind of patients.

Methods. 232 stable and optimally treated chronic HF patients were enrolled. We excluded subjects suffering from valvular diseases or atrial fibrillation. They underwent blood sampling and echocardiographic examination. The primary endpoint of the study was cardiovascular death and/or HF hospitalization in the first year after enrolment.

Results. 49 patients reached the primary endpoint. RDW best cut-off at ROC curve was $14.45 \%$. Univariate analysis associated mitral regurgitation grade, left ventricular ejection fraction (LVEF), posterior wall thickness (PWT), LV mass index, and RDW $>14.45 \%$ to the primary endpoint. Multivariate regression analysis showed that LVEF, PWT, and RDW $>14.45 \%$ predict the primary endpoint. Area under ROC curve was 0.808 for LVEF, 0.762 for NYHA class, and 0.761 for RDW.
\end{abstract}

Corresponding author: Dr. Enrico Vizzardi, Department of Medical and Surgical Specialties, Radiological Sciences and Public Health, Section of Cardiovascular Diseases, University of Brescia, Piazzale Spedali Civili 1, 25123 Brescia, Italy. Tel.: +39.030 .3995679 - Fax: +39.030 .3996801 .

E-mail: enrico.vizzardi@tin.it

Key words: Red cell distribution width; heart failure; prognostic value; echocardiography.

Parole chiave: Red cell distribution width; scompenso cardiaco; valore prognostico; ecocardiografia.

Received for publication: 26 September 2015

Accepted for publication: 9 May 2016

(C) Copyright E. Vizzardi et al., 2015

Tipografia PI-ME Editrice, Italy

Monaldi Archives for Chest Disease Pulmonary Series 2015; 84.59

doi: 10.4081/monaldi.2015.59

This article is distributed under the terms of the Creative Commons Attribution Noncommercial License (by-nc 4.0) which permits any noncommercial use, distribution, and reproduction in any medium, provided the original author(s) and source are credited.
Conclusion. In chronic HF patients RDW is a better predictor of adverse outcome than several echocardiographic parameters associated to outcome itself ( $\mathrm{LV}$ mass index, mitral regurgitation grade), predicts prognosis even adjusting for those parameters, age and NYHA class, and is associated to several echocardiographic measurements. In conclusion, RDW can expand our tool bag in order to better follow-up these patients.

\section{Riassunto}

Scopo. Il red cell distribution width (RDW) è una misura di anisocitosi. Valori elevati sono fortemente associati ad esiti sfavorevoli in plurime condizioni, tra cui lo scompenso cardiaco (SC) cronico. Lo scopo di questo studio era paragonare il suo ruolo prognostico con quello dei parametri ecocardiografici in questo tipo di pazienti.

Metodi. Sono stati arruolati 232 pazienti affetti da SC cronico, stabili e con terapia ottimizzata. Sono stati esclusi i soggetti con valvulopatie o fibrillazione atriale. I pazienti sono stati sottoposti a prelievo di sangue ed ecocardiogramma. L'endpoint primario dello studio consisteva in morte cardiovascolare e/o ospedalizzazione per SC entro un anno dall'arruolamento.

Risultati. 49 pazienti hanno raggiunto l'endpoint primario. Il miglior cut-off di RDW alla curva ROC è stato $14.45 \%$. L'analisi uni variata ha associato il grado di insufficienza mitralica, la frazione di eiezione ventricolare sinistra (FEVS), lo spessore della parete posteriore del ventricolo sinistro (PP), la massa ventricolare sinistra indicizzata e RDW $>14.45 \%$ all'endpoint primario. La regressione multivariata ha mostrato che FEVS, PP e RDW>14.45\% predicono l'endpoint primario. L'area sotto la curva ROC è risultata 0.808 per la FEVS, 0.762 per la classe NYHA e 0.761 per l'RDW.

Conclusione. In pazienti con SC cronico l'RDW è un miglior predittore di outcome sfavorevole rispetto a numerosi parametri ecocardiografici associati allo stesso outcome (massa ventricolare sinistra indicizzata, grado di insufficienza mitralica), predice la prognosi anche se corretto per quei parametri, per l'età e per la classe NYHA, ed è associato a numerose misure ecocardiografiche. In conclusione, l'RDW può ampliare il nostro armamentario per seguire meglio nel tempo questi pazienti.

\section{Introduction}

Red cell distribution width (RDW) is a measure of erythrocytes size variability (anisocytosis); in particular it represents the coefficient of 
variation of the red cell mean corpuscular volume (MCV) and its normal values range from 12 to $17 \%$ [1]. Typically, RDW increases in haemolytic diseases, conditions causing reticulocytosis, thrombotic thrombocytopenic purpura, inflammatory bowel diseases, and pregnancy [2-6]. However, recently, RDW has been found a good predictor marker for heart failure (HF) patients with reduced left ventricular ejection fraction (LVEF) (CHARM study) [7], with preserved LVEF [8], and for subject with prior myocardial infarction without HF (CARE study) [9]. Although these and other demonstrations [10-14], including a meta-analysis [15], no studies to our knowledge have yet investigated the predictive ability of RDW compared to traditionally evaluated echocardiographic parameters in chronic HF patients. We thus sought to examine this aspect in order to find how useful could routine RDW assessment be in this kind of subjects.

\section{Methods}

\section{Subjects}

From September 2012 to September 2013 we consecutively enrolled 232 stable and optimally treated patients affected by chronic HF and followed by the Heart Failure Center of the Cardiologic Unit of University Civil Hospital of Brescia, Italy. Inclusion criteria were: patients with clinically stable HF caused by LV systolic dysfunction (defined by LVEF $<45 \%$ or LV end-diastolic diameter (LVEDD) $\geq 32 \mathrm{~mm} / \mathrm{m}^{2}$ in sinus rhythm) with at least one hospitalization for HF in the previous year, ischaemic or idiopathic aetiology. We excluded patients with: primary valve heart diseases or congenital heart diseases; recent ( $<3$ months) unstable angina or acute myocardial infarction. By enrolment, patients had been clinically evaluated with 12-derivative electrocardiography (ECG), Doppler echocardiography, and blood sampling. The primary endpoint of the study was cardiovascular death and/or HF hospitalization in the first year after enrolment. We state that our study complies with the Declaration of Helsinki; Ethical Committee approval was waived because of the retrospective analysis of the study according to the national law regulating observational retrospective studies (law no. 11960, released on 13 July, 2004). However, all patients gave their informed consent to access their data for scientific purposes.

\section{Echocardiography}

Echocardiographic examinations were performed using Vivid 7 machine (GE Healthcare, Milwaukee, SI, USA) with a $3.5 \mathrm{MHz}$ transducer. Digital loops were stored on the hard disk of the echocardiograph for on-line and off-line analyses and transferred to a workstation EchoPac, Vingmed (GE Healthcare) for off-line analysis. Participants were studied in the left lateral decubitus position and images acquired from standard parasternal and apical windows. All studies were read by two echocardiographists blinded to all patient informations. The echocardiographic measurements of the left ventricular internal dimension, peak $\mathrm{E}$ wave and A wave of mitral inflow, left atrial size were performed off-line, according to recommendations of the American Society of Echocardiography [16,17]. LV volumes and ejection fraction were obtained by the modified biplane Simpson method. LV mass was calculated according to the formula: $0.8 \times$ [1.04 x (LVEDD+ PWT + SWT $)^{3}-$ $\left.\left.(\mathrm{LVEDD})^{3}\right)\right]+0.6(\mathrm{~g})$, in which PWT is posterior wall thickness, and SWT septal wall thickness, all measured in $\mathrm{cm}$.

\section{Laboratory analysis}

Blood was sampled for the measurement of routine chemistry including total cholesterol, triglycerides, creatinine, heamoglobin, MCV and RDW. In particular, RDW was promptly measured (within 5 minutes) after blood collection with the use of the Coulter LH 780 analyzer (Beckman Coulter Inc., FL) at our hospital laboratory. Glomerular filtration rate was estimated (eGFR) according to Cockroft and Gault's formula.

\section{Statistical analysis}

Continue variables were expressed as mean \pm standard deviation (SD) while categorical ones as frequency (n) and percentage of the sample. Continue variables were visually tested to confirm a normal distribution by $Q-Q$ plots and then compared by unpaired samples Student's t test, while categorical ones with $\chi^{2}$ test and Fisher's exact test if dichotomic. For RDW a receiver-operating characteristic (ROC) curve was created regarding adverse outcome, and a cut-off with both best specificity and sensitivity was chosen (resulting 14.45\%). Univariate analysis including proportion of RDW $>14.45 \%$ and those parameters which correlated to the outcome was elaborated to investigate which of them remained statistically significant respect of the outcome. Multivariate logistic regression was run to calculate odds ratios (ORs) together with their 95\% confidence intervals (CIs) for proportion of RDW $>14.45 \%$ and those variables that significantly correlated to the outcome, in order to analyze their ability to predict the outcome. Finally, ROC curves were used to determine the predictiveness of cardiovascular death or HF hospitalization for the parameters that resulted statistically correlated with adverse outcome; area under ROC curves (AUROCs) and their CIs were also calculated. In this case we obviously used RDW as a continuous variable. $P$ values less than 0.05 were considered statistically significant. Data were analyzed using SPSS statistical package for Windows (Version 20.0; SPSS, Inc., Chicago, IL, USA).

\section{Results}

During one-year follow-up we found 3 cases of death (1.3\%) and 46 hospitalizations (19.8\%), while 183 subjects (78.9\%) did not experience the study primary endpoint. Demographic, clinical, and echocardiographic characteristics are listed in Table 1; they are reported for the whole population and for the two groups according to follow-up events. People who died or were hospitalized significantly differed with those who experienced positive outcome respect of age (older), sex (female), diabetes mellitus, NYHA functional class (worse), eGFR (reduced), LVEF (lower), LVEDD index (greater), PWT (thicker), LV mass index (heavier), mitral regurgitation grade (worse), left atrial volume (larger), E/A ratio (more altered), and RDW (bigger). Interestingly, heamoglobin value did not significantly differ between the two groups ( $\mathrm{p}=0.084$ ), albeit being reduced in those who experienced the study primary endpoint. ROC curve for RDW suggested $14.45 \%$ as best cut-off value, with a sensibility of $76 \%$ and a specificity of $64 \%$ (Table 2). Moreover, we carried out an univariate analysis including RDW $>14.45 \%$ and parameters correlated to the study primary endpoint, demonstrating that LVEF, PWT, LV mass index, mitral regurgitation grade, and RDW $>14.45 \%$ still remained associated to the study primary endpoint, even adjusting for other considered parameters (Table 3). In the same way, we ran a multivariate logistic regression with the same parameters; LVEF, PWT, and RDW $>14.45 \%$ significantly predicted the study primary endpoint, even taken together (Table 4). In particular, patients with RDW value above $14.45 \%$ had 3.894 times (95\% CI: 1.042-14.555) the risk of cardiovascular death and/or HF hospitalization than those with RDW below or equal to that cut-off. Finally, the study primary endpoint-related ROC curves parameters of NYHA functional class, LVEF, PWT, LV mass index, age, mitral regurgitation grade, eGFR, left atrial volume, E/A ratio, LVEDD, and RDW $>14.45 \%$ 
Table 1. Demographic and clinical data of the study population in general and divided according to the outcome.

\begin{tabular}{|c|c|c|c|c|}
\hline Parameter & Whole population $(n=232)$ & Adverse outcome (n=49) & Positive outcome $(\mathrm{n}=183)$ & $p$ \\
\hline Age (years) & $67 \pm 12$ & $71 \pm 8$ & $66 \pm 13$ & 0.001 \\
\hline Sex & $\begin{array}{c}\text { Male: } 186(80.2 \%) \\
\text { Female: } 46(19.8 \%)\end{array}$ & $\begin{array}{c}\text { Male: } 33(67.3 \%) \\
\text { Female: } 16(32.7 \%)\end{array}$ & $\begin{array}{c}\text { Male: } 153(83.6 \%) \\
\text { Female: } 30(16.4 \%)\end{array}$ & 0.015 \\
\hline BMI $\left(\mathrm{kg} / \mathrm{m}^{2}\right)$ & $27.3 \pm 4.4$ & $28.2 \pm 4.4$ & $27.0 \pm 4.4$ & 0.097 \\
\hline Etiology & $\begin{array}{l}\text { Ischemic: } 141 \text { (60.8\%) } \\
\text { Idiopathic: } 91(39.2 \%)\end{array}$ & $\begin{array}{l}\text { Ischemic: } 32(65.3 \%) \\
\text { Idiopathic: } 17(34.7 \%)\end{array}$ & $\begin{array}{l}\text { Ischemic: } 109 \text { (59.6\%) } \\
\text { Idiopathic: } 74 \text { (40.4\%) }\end{array}$ & 0.513 \\
\hline Hypertension & $113(48.7 \%)$ & $27(55.1 \%)$ & $86(47.0 \%)$ & 0.338 \\
\hline Diabetes mellitus & $75(32.2 \%)$ & $22(44.9 \%)$ & $53(29.0 \%)$ & 0.037 \\
\hline NYHA class & $\begin{array}{l}\text { I: } 42(18.1 \%) \\
\text { II: } 166(71.6 \%) \\
\text { III: } 24(10.3 \%) \\
\text { IV: } 0(0.0 \%)\end{array}$ & $\begin{array}{l}\text { I: } 0(0.0 \%) \\
\text { II: } 32(65.3 \%) \\
\text { III: } 17(34.7 \%) \\
\text { IV: } 0(0.0 \%)\end{array}$ & $\begin{array}{l}\text { I: } 42(23.0 \%) \\
\text { II: } 134(73.2 \%) \\
\text { III: } 7(3.8 \%) \\
\text { IV: } 0(0.0 \%) \\
\end{array}$ & $<0.001$ \\
\hline Pace-maker & $28(12.1 \%)$ & $6(12.2 \%)$ & $22(12.0 \%)$ & 1.000 \\
\hline ICD & $88(37.9 \%)$ & $23(46.9 \%)$ & $65(35.5 \%)$ & 0.184 \\
\hline CRT & $104(44.8 \%)$ & $25(51.0 \%)$ & $79(43.2 \%)$ & 0.337 \\
\hline SBP (mmHg) & $120 \pm 15$ & $120 \pm 16$ & $118 \pm 14$ & 0.442 \\
\hline $\mathrm{DBP}(\mathrm{mmHg})$ & $72 \pm 9$ & $73 \pm 9$ & $72 \pm 9$ & 0.642 \\
\hline Heart rate (bpm) & $67 \pm 12$ & $69 \pm 13$ & $67 \pm 11$ & 0.170 \\
\hline Total cholesterol (mg/dL) & $179 \pm 38$ & $182 \pm 42$ & $178 \pm 37$ & 0.537 \\
\hline Triglycerides (mg/dL) & $149 \pm 114$ & 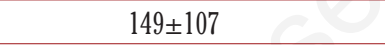 & $149 \pm 117$ & 0.996 \\
\hline Creatinine (mg/dL) & $1.33 \pm 0.89$ & $1.39 \pm 0.50$ & $1.31 \pm 0.97$ & 0.575 \\
\hline eGFR $\left(\mathrm{mL} / \mathrm{min} / \mathrm{m}^{2}\right)$ & $64 \pm 31$ & $55 \pm 28$ & $67 \pm 31$ & 0.017 \\
\hline Haemoglobin (g/dL) & $13.5 \pm 1.5$ & $13.2 \pm 1.5$ & $13.6 \pm 1.4$ & 0.084 \\
\hline $\operatorname{MCV}\left(\mu m^{3}\right)$ & $91.5 \pm 6.1$ & $91.0 \pm 6.6$ & $91.7 \pm 6.0$ & 0.537 \\
\hline RDW (\%) & $14.6 \pm 1.6$ & $15.6 \pm 1.8$ & $14.4 \pm 1.4$ & $<0.001$ \\
\hline LVEF (\%) & $36 \pm 8$ & $31 \pm 8$ & $37 \pm 7$ & $<0.001$ \\
\hline LVEDD (mm) & $36 \pm 4$ & $37 \pm 4$ & $36 \pm 4$ & 0.020 \\
\hline $\operatorname{LVESD}(\mathrm{mm})$ & $20 \pm 14$ & $18 \pm 16$ & $20 \pm 14$ & 0.395 \\
\hline SWT (mm) & $11 \pm 2$ & $10 \pm 2$ & $11 \pm 2$ & 0.203 \\
\hline PWT (mm) & $10 \pm 1$ & $10 \pm 2$ & $9 \pm 1$ & 0.035 \\
\hline LV mass index $\left(\mathrm{g} / \mathrm{m}^{2}\right)$ & $163 \pm 36$ & $174 \pm 36$ & $161 \pm 36$ & 0.023 \\
\hline Mitral regurgitation grade & $\begin{array}{c}\text { None: } 7(3.0 \%) \\
\text { Mild: } 103(44.4 \%) \\
\text { Moderate: } 82(35.3 \%) \\
\text { Medium: } 34(14.7 \%) \\
\text { Severe: } 6(2.6 \%)\end{array}$ & $\begin{array}{c}\text { None: } 2(4.1 \%) \\
\text { Mild: } 12(24.5 \%) \\
\text { Moderate: } 19(38.8 \%) \\
\text { Medium: } 10(20.4 \%) \\
\text { Severe: } 6(12.2 \%)\end{array}$ & $\begin{array}{c}\text { None: } 5(2.8 \%) \\
\text { Mild: } 91(49.7 \%) \\
\text { Moderate: } 63(34.4 \%) \\
\text { Medium: } 24(13.1 \%) \\
\text { Severe: } 0(0.0 \%)\end{array}$ & $<0.001$ \\
\hline Left atrial volume (mL) & $47 \pm 5$ & $49 \pm 5$ & $46 \pm 5$ & $<0.001$ \\
\hline E/A ratio & $1.00 \pm 0.59$ & $1.31 \pm 0.88$ & $0.92 \pm 0.45$ & 0.009 \\
\hline E/E' ratio & $9.6 \pm 3.2$ & $10.1 \pm 4.3$ & $9.4 \pm 2.9$ & 0.393 \\
\hline
\end{tabular}

CRT, cardiac resynchronization therapy; DBP, diastolic blood pressure; eGFR, estimated glomerular filtration rate; ICD, implantable cardioverter defibrillator; LV, left ventricular; LVEDD, left ventricular end-diastolic diameter; LVEF, left ventricular ejection fraction; LVESD, left ventricular end-systolic diameter; MCV, mean corpuscular volume; NYHA, New York Heart Association; PWT, posterior wall thickness; RDW, red cell distribution width; SBP, systolic blood pressure; SWT, septal wall thickness.

are represented in Table 2, revealing that the best predictor of cardiovascular death or HF hospitalization after LVEF and NYHA functional class was $\mathrm{RDW}>14.45 \%$.

\section{Discussion}

In the present study we found that: 1) RDW is a better predictor of cardiovascular death and/or HF hospitalization in HF patients than several echocardiographic parameters associated to outcome itself (LV mass index, mitral regurgitation grade); 2) RDW predicts HF prognosis even adjusting for echocardiographic parameters, age and NYHA functional class.

First of all we pinpoint that the subjects in this study did not suffer from haemolytic conditions, known bone marrow dysfunction, chronic inflammatory diseases, renal, thyroid, hepatic pathologies, had not iron, folic acid, or vitamin B12 deficiency (as shown by MCV value), nor received blood transfusions. In fact, the cited conditions are responsible of RDW alterations which can be potential confounders regarding HF prognosis. Moreover, RDW may also reflect ethnicity, neurohumoral activation, and use of any medications, parameters reasonably homogeneous in our population [18]. On the other hand the study primary 
Table 2. Area under receiver-operating characteristic (AUROC) curves for parameters statistically significant in Table 1 respect of adverse outcome (cardiovascular death and/or HF hospitalization).

\begin{tabular}{lccc} 
Parameter & $p$ & AUROC & $95 \%$ CI of AUROC \\
LVEF $(\%)$ & $<0.001$ & 0.808 & $0.716-0.900$ \\
\hline NYHA class & $<0.001$ & 0.762 & $0.672-0.853$ \\
\hline RDW & $<0.001$ & 0.761 & $0.673-0.850$ \\
\hline eGFR $\left(\mathrm{mL} / \mathrm{min} / \mathrm{m}^{2}\right)$ & $<0.001$ & 0.755 & $0.665-0.844$ \\
\hline Mitral regurgitation grade & $<0.001$ & 0.721 & $0.613-0.830$ \\
\hline Age (years) & 0.001 & 0.691 & $0.605-0.776$ \\
\hline Left atrial volume $(\mathrm{mL})$ & 0.004 & 0.665 & $0.560-0.771$ \\
\hline E/A ratio & 0.014 & 0.641 & $0.518-0.764$ \\
\hline LVEDD $(\mathrm{mm})$ & 0.021 & 0.633 & $0.517-0.749$ \\
\hline LV mass index $\left(\mathrm{g} / \mathrm{m}^{2}\right)$ & 0.036 & 0.620 & $0.517-0.724$ \\
\hline PWT $(\mathrm{mm})$ & 0.258 & 0.565 & $0.457-0.673$ \\
\hline
\end{tabular}

LVEF, left ventricular ejection fraction; NYHA, New York Heart Association; RDW, red cell distribution width; eGFR, estimated glomerular filtration rate; LVEDD, left ventricular end-diastolic diameter; LV, left ventricular; PWT, posterior wall thickness.

Table 3. Univariate analysis regarding $\mathrm{RDW}>14.45 \%$ and parameters statistically significant in Table 1 respect of adverse outcome (cardiovascular death and/or HF hospitalization).

\begin{tabular}{lc} 
Parameter & $p$ \\
LVEF $(\%)$ & $<0.001$ \\
\hline NYHA class & 0.090 \\
\hline RDW $>14.45 \%$ & 0.021 \\
\hline eGFR $\left(\mathrm{mL} / \mathrm{min} / \mathrm{m}^{2}\right)$ & 0.749 \\
\hline Mitral regurgitation grade & 0.048 \\
\hline Age (years) & 0.450 \\
\hline Left atrial volume $(\mathrm{mL})$ & 0.525 \\
\hline E/A ratio & 0.104 \\
\hline LVEDD $(\mathrm{mm})$ & 0.815 \\
\hline LV mass index $\left(\mathrm{g} / \mathrm{m}^{2}\right)$ & 0.042 \\
\hline PWT $(\mathrm{mm})$ & 0.026 \\
\hline Sex & 0.097
\end{tabular}

LVEF, left ventricular ejection fraction; NYHA, New York Heart Association; RDW, red cell distribution width; eGFR, estimated glomerular filtration rate; LVEDD, left ventricular end-diastolic diameter; LV, left ventricular; PWT, posterior wall thickness.

Table 4. Multivariate logistic regression analysis regarding RDW $>14.45 \%$ and parameters statistically significant in Table 1 respect of adverse outcome (cardiovascular death and/or HF hospitalization). Nagelkerke $\mathrm{R}^{2}=0.608$.

\begin{tabular}{lccc} 
Parameter & $\boldsymbol{P}$ & OR & $95 \%$ CI for OR \\
LVEF $(\%)$ & 0.006 & 0.858 & $0.769-0.957$ \\
\hline NYHA class & 0.084 & 4.169 & $0.824-21.082$ \\
\hline RDW $>14.45 \%$ & 0.043 & 3.894 & $1.042-14.555$ \\
\hline eGFR $\left(\mathrm{mL} / \mathrm{min} / \mathrm{m}^{2}\right)$ & 0.952 & 1.001 & $0.968-1.035$ \\
\hline Mitral regurgitation grade & 0.209 & 1.715 & $0.740-3.977$ \\
\hline Age (years) & 0.346 & 1.040 & $0.958-1.129$ \\
\hline Left atrial volume (mL) & 0.812 & 1.020 & $0.868-1.197$ \\
\hline E/A ratio & 0.516 & 1.385 & $0.518-3.699$ \\
\hline LVEDD $(\mathrm{mm})$ & 0.485 & 1.089 & $0.858-1.383$ \\
\hline LV mass index $\left(\mathrm{g} / \mathrm{m}^{2}\right)$ & 0.072 & 0.975 & $0.948-1.002$ \\
\hline PWT (mm) & 0.027 & 1.984 & $1.080-3.645$ \\
\hline Sex & 0.232 & 0.412 & $0.096-1.764$ \\
\hline Diabetes mellitus & 0.058 & 3.781 & $0.958-14.920$ \\
\hline
\end{tabular}

LVEF, left ventricular ejection fraction; NYHA, New York Heart Association; RDW, red cell distribution width; eGFR, estimated glomerular filtration rate; LVEDD, left ventricular end-diastolic diameter; LV, left ventricular; PWT, posterior wall thickness. endpoint group had a significantly reduced eGFR. In addition, every effort was made to analyze as quickly as possible (within 5 minutes) blood samples because longer processing time can cause abnormal results in RDW evaluation. Of note, RDW predictive capability was not associated to anaemia in our population, which is another prognostic factor for HF [19]. In addition, parameters widely associated with adverse prognosis are not associated to it in this study (i.e., diabetes mellitus, eGFR, diastolic dysfunction, mitral regurgitation grade, left atrial volume, etc.). We hypothesized that our patients were too much homogeneous and our population too small to allow these parameters catching a difference regarding the study primary endpoint.

LVEF and functional capacity according to NYHA are the two most important parameters evaluated in HF. In our study RDW resulted slightly less predictive than them (AUROC 0.761 vs. 0.808 or 0.762 , respectively). Moreover, the correlation between RDW and both LVEF and NYHA class was found strongly significant. This result confirms those of previous studies [7,10-15]. Despite this, we hereby first suggested that RDW assessment in stable and closely followed-up chronic HF patients is more useful than mitral regurgitation grade, LV mass index, PWT, LVEDD, left atrial size, and E/A ratio. Even adjusting for them, RDW maintained its prognostic role. In addition, RDW is present in any standard complete blood count and is clearly less expensive and easier to obtain than echocardiographic examination, suggesting that it could be a very useful tool in every clinical setting.

RDW is a statistical parameter whose role in HF is still difficult to understand. Three recent studies demonstrated that its value in this context is independent of anaemia [14,20,21]. Förhécz et al., in fact, suggested that RDW is nonspecifically associated to iron deficiency, inflammation, ineffective erythropoiesis, malnutrition, neurohormonal activation, and renal impairment, which are all linked to worsening HF [22].

There are potential limitations of this study. First, we did not evaluate inflammation markers, NT-proBNP, neurohormonal parameters (renin, angiotensin II, epinephrine). Second, we did not directly measure vitamin B12 and folic acid; nevertheless our population is at least only slightly anaemic and this aspect could be negligible.

\section{Conclusions}

This study confirms the prognostic role of RDW in chronic HF and may contribute to expand our tool bag in order to better follow-up these patients. Further studies are needed to understand the true significance of RDW increasing in chronic HF subjects.

\section{References}

1. Schweiger DJ. Red cell distribution width in sickle cell anemia. Am J Med Technol 1981;47:231-3.

2. Das Gupta A, Hegde C, Mistri R. Red cell distribution width as a measure of severity of iron deficiency in iron deficiency anaemia. Indian J Med Res 1994;100:177-83.

3. Docci D, Delvecchio C, Gollini C, Turci F, Baldrati L, Gilli P. Red blood cell volume distribution width (RDW) in uraemic patients on chronic haemodialysis. Int J Artif Organs 1989;12:170-4.

4. Nagajothi N, Braverman A. Elevated red cell distribution width in the diagnosis of thrombotic thrombocytopenic purpura in patients presenting with anemia and thrombocytopenia. South Med J 2007;100:257-9.

5. Clarke K, Sagunarthy R, Kansal S. RDW as an additional marker in inflammatory bowel disease/undifferentiated colitis. Dig Dis Sci 2008;53:251-3.

6. Shehata HA, Ali MM, Evans-Jones JC, et al. Red cell distribution width 
(RDW) changes in pregnancy. Int J Gynaecol Obstet 1998;62:43-6.

7. Felker GM, Allen LA, Pocock SJ, et al. Red cell distribution width as a novel prognostic marker in heart failure: data from the CHARM Program and the Duke Databank. J Am Coll Cardiol 2007;50:40-7.

8. Celik A, Koc F, Kadi H, et al. Relationship between red cell distribution width and echocardiographic parameters in patients with diastolic heart failure. Kaohsiung J Med Sci 2012;28:165-72.

9. Tonelli M, Sacks F, Arnold M, et al. Relation between red blood cell distribution width and cardiovascular event rate in people with coronary disease. Circulation 2008;117:163e8.

10. Cauthen CA, Tong W, Jain A, Tang WH. Progressive rise in red cell distribution width is associated with disease progression in ambulatory patients with chronic heart failure. J Card Fail 2012;18:146-52.

11. Oh J, Kang SM, Won H, et al. Prognostic value of change in red cell distribution width 1 month after discharge in acute decompensated heart failure patients. Circ J 2012;76:109-16.

12. Bonaque JC, Pascual-Figal DA, Manzano-Fernández S, et al. Red blood cell distribution width adds prognostic value for outpatients with chronic heart failure. Rev Esp Cardiol (Engl Ed) 2012;m65:606-12.

13. Núñez J, Núñez E, Rizopoulos D, et al. Red blood cell distribution width is longitudinally associated with mortality and anemia in heart failure patients. Circ J 2014;78:410-8.

14. Al-Najjar Y, Goode KM, Zhang J, et al. Red cell distribution width: an inexpensive and powerful prognostic marker in heart failure. Eur J Heart Fail 2009;11:1155-62.

15. Huang YL, Hu ZD, Liu SJ, et al. Prognostic value of red blood cell distribution width for patients with heart failure: a systematic review and meta-analysis of cohort studies. PLoS One 2014;9:e104861.

16. Nagueh SF, Appleton CP, Gillebert TC, et al. Recommendations for the evaluation of left ventricular diastolic function by echocardiography. J Am Soc Echocardiogr 2009;22:107-33.

17. Lang RM, Bierig M, Devereux RB, et al. Recommendations for chamber quantification: a report from the American Society of Echocardiography's Guidelines and Standards Committee and the Chamber Quantification Writing Group, developed in conjunction with the European Association of Echocardiography, a branch of the European Society of Cardiology. J Am Soc Echocardiogr 2005;18:1440-63.

18. Fici F, Celik T, Balta S, et al. Comparative effects of nebivolol and metoprolol on red cell distribution width and neutrophil/lymphocyte ratio in patients with newly diagnosed essential hypertension. J Cardiovasc Pharmacol 2013;62:388-93.

19. Anand IS. Pathophysiology of anemia in heart failure. Heart Fail Clin 2010;6:279-88.

20. van Kimmenade RRJ, Mohammed AA, Uthamalingam S, et al. Red blood cell distribution width and one-year mortality in acute heart failure. Eur J Heart Fail 2010;12:129-16.

21. Pascual-Figal DA, Bonaque JC, Redondo B, et al. Red blood cell distribution width predicts long-term outcome regardless of anaemia status in acute heart failure patients. Eur J Heart Fail 2009;11: 840-6.

22. Förhécz Z, Gombos T, Borgulya G, et al. Red cell distribution width in heart failure: prediction of clinical events and relationship with markers of ineffective erythropoiesis, inflammation, renal function, and nutritional state. Am Heart J 2009;158:659-66.

23. Oh J, Kang SM, Hong N, et al. Relation between red cell distribution width with echocardiographic parameters in patients with acute heart failure. J Card Fail 2009;5:517-22. 